ISSN 2078-3744. Вісник Львів. ун-ту. Серіл мех.-мат. 2019. Випуск 87. С. 109-121

Visnyk of the Lviv Univ. Series Mech. Math. 2019. Issue 87. P. 109-121

http://publications.lnu.edu.ua/bulletins/index.php/mmf

doi: http://dx.doi.org/10.30970/vmm.2019.87.109-121

УДК 517.95

口ㅁ

\title{
INVERSE SOURCE PROBLEM FOR SEMILINEAR TIME FRACTIONAL EQUATION
}

\section{Halyna LOPUSHANSKA, Olga MYAUS}

\author{
Ivan Franko National University of Lviv, \\ Universitetska Str., 1, 79000, Lviv, Ukraine \\ e-mail: lhp@ukr.net \\ Lviv Polytechnic National University, \\ Bandera Str., 12, 79013, Lviv, Ukraine \\ e-mail: myausolya2016@gmail.com
}

\begin{abstract}
We study the inverse problem of the restoration dependent on time continuous factor in the right-hand side of a semilinear time fractional equation. We find sufficient conditions of uniqueness of both classical and generalized solution under integral type over-determination condition.

Key words: fractional derivative, inverse problem, over-determination condition, Green vector-function, integral equation.
\end{abstract}

Equations with fractional derivatives and inverse problems for them arise in many branches of science and engineering with memory being taken into account. Some inverse problems to diffusion-wave equations with different unknown functions or parameters (source, order of partial derivative, older or minor coefficient, boundary or initial data) were investigated, for example, in [1-[11]. In particular, in [1, 3, 4, 6, 7] integral type over-determination conditions were used in the inverse source and coefficient problems for such equations.

In this paper, we find the conditions of uniqueness of the solution $(u, g)$ of the inverse problem

$$
\begin{gathered}
D_{t}^{\alpha} u-\Delta u=g(t) F_{0}(x, t, u), \quad(x, t) \in \Omega \times(0, T], \\
u(x, t)=0, \quad(x, t) \in \partial \Omega \times[0, T], \\
u(x, 0)=F_{1}(x), \quad x \in \bar{\Omega}, \\
\int_{\Omega} u(x, t) \varphi_{0}(x) d x=F_{2}(t), t \in[0, T]
\end{gathered}
$$

2010 Mathematics Subject Classification: 35S15

(C) Lopushanska,H., Myaus, O., 2019 
with the Caputo derivative $D_{t}^{\alpha} u$ of order $\alpha \in(0,1)$ in the case of regular data and the inverse problem

$$
\begin{gathered}
u_{t}^{(\alpha)}-\Delta u=g(t) F_{0}(x, t, u), \quad(x, t) \in \Omega \times(0, T], \\
u(x, t)=0, \quad(x, t) \in \partial \Omega \times(0, T], \\
u(x, 0)=F_{1}(x), \quad x \in \Omega, \\
\left(u(\cdot, t), \varphi_{0}(\cdot)\right)=F_{2}(t), \quad t \in[0, T]
\end{gathered}
$$

with the Riemann-Liouville derivative $u_{t}^{(\alpha)}$ in the case of given distribution $F_{1}$. Here $\Omega$ is a bounded domain in $\mathbb{R}^{n}, n \in \mathbb{N}(n \geq 2)$ with the boundary $\partial \Omega$ of the class $C^{\infty}$, $\left(u(\cdot, t), \varphi_{0}(\cdot)\right)$ stands for the value of an unknown distribution $u$ on a given test function $\varphi_{0}$ for every $t \in[0, T]$.

We note that inverse problems for semilinear parabolic and ultraparabolic equations with derivatives of the integer orders were investigated, for example, in [12, 13. The coefficient inverse problem for a semilinear time fractional telegraph equation in the case of regular data was studied in [6].

We shall use the method of Green's functions [14]-[18].

\section{UNIQUENESS OF THE CLASSICAL SOLUTION}

Let $Q=\Omega \times(0, T], f * g$ be the convolution of functions $f$ and $g$,

$$
f_{\lambda}(t)=\frac{\theta(t) t^{\lambda-1}}{\Gamma(\lambda)} \text { for } \lambda>0 \quad \text { and } \quad f_{\lambda}(t)=f_{1+\lambda}^{\prime}(t) \text { for } \lambda \leqslant 0,
$$

where $\Gamma(t)$ is the Gamma-function, $\theta(t)$ is the Heaviside function. Note that

$$
f_{\lambda} * f_{\mu}=f_{\lambda+\mu}
$$

the Riemann-Liouville derivative $v_{t}^{(\alpha)}(x, t)$ of order $\alpha>0$ is defined by the formula

$$
v_{t}^{(\alpha)}(x, t)=f_{-\alpha}(t) * v(x, t),
$$

the Caputo fractional derivative of order $\alpha \in(0,1)$ is defined as follows [19, 20]

$$
D_{t}^{\alpha} v(x, t)=\frac{1}{\Gamma(1-\alpha)}\left[\frac{\partial}{\partial t} \int_{0}^{t} \frac{v(x, \tau)}{(t-\tau)^{\alpha}} d \tau-\frac{v(x, 0)}{t^{\alpha}}\right]=v_{t}^{(\alpha)}(x, t)-f_{1-\alpha}(t) v(x, 0) .
$$

Let $\beta=\left(\beta_{1}, \ldots, \beta_{n}\right)$ with $\beta_{j} \in \mathbb{Z}_{+}, j=1,2, \ldots, n,|\beta|=\beta_{1}+\cdots+\beta_{n}, \gamma \in(0,1)$, $D^{\beta} \varphi(x)=\frac{\partial^{|\beta|} \varphi(x)}{\partial x_{1}^{\beta_{1}} \ldots \partial x_{n}^{\beta_{n}}}, C^{\gamma}(\Omega)\left(C^{\gamma}(Q)\right)$ be the space of bounded continuous functions on $\Omega$ ( $Q$, respectively) satisfying the Hölder continuity condition (Hölder continuity condition with respect to space variables), $C^{\gamma}(\bar{\Omega})=C^{\gamma}(\Omega) \cap C(\bar{\Omega})$,

$$
\begin{gathered}
C^{m+\gamma}(\Omega)=\left\{\varphi \in C^{m}(\Omega): D^{\beta} \varphi \in C^{\gamma}(\Omega) \text { for }|\beta|=m\right\}, \\
C^{m+\gamma}(Q)=\left\{\varphi \in C^{m}(Q): D^{\beta} \varphi \in C^{\gamma}(Q) \text { for }|\beta|=m\right\}, m \in \mathbb{N}, \\
C^{2, \alpha}(Q)=\left\{v \in C^{2+\gamma}(Q): D_{t}^{\alpha} v \in C^{\gamma}(Q)\right\}, \quad C^{2, \alpha}(\bar{Q})=C^{2, \alpha}(Q) \cap C(\bar{Q}) .
\end{gathered}
$$


Definition 1. A pair of functions $(u, g) \in C^{2, \alpha}(\bar{Q}) \times C[0, T]$ satisfying the equation (1) on $Q$ and the conditions (2) is called a classical solution of problem (1), (2).

The definition implies the consistency conditions

$$
\left.F_{1}\right|_{\partial \Omega}=0, \quad \int_{\Omega} F_{1}(x) \varphi_{0}(x) d x=F_{2}(0) .
$$

Definition 2. A vector-function $\left(G_{0}(x, t, y, \tau), G_{1}(x, t, y)\right)$ is called the Green's vectorfunction of the problem

$$
\begin{gathered}
D_{t}^{\alpha} u(x, t)-\Delta u(x, t)=g_{0}(x, t), \quad(x, t) \in Q, \\
\left.u\right|_{\partial \Omega \times[0, T]}=0, \quad u(x, 0)=g_{1}(x), \quad x \in \bar{\Omega}
\end{gathered}
$$

if under smooth finite $g_{0}, g_{1}$ the function

$$
u(x, t)=\int_{0}^{t} d \tau \int_{\Omega} G_{0}(x, t, y, \tau) g_{0}(y, \tau) d y+\int_{\Omega} G_{1}(x, t, y) g_{1}(y) d y, \quad(x, t) \in \bar{Q}
$$

is the classical solution (in $C^{2, \alpha}(\bar{Q})$ ) of this problem.

It is known (see, for example, [15]) that such Green's vector-function exists and for bounded $g_{0} \in C^{\gamma}(Q), g_{1} \in C^{\gamma}(\Omega)$ the unique solution $u \in C^{2, \alpha}(\bar{Q})$ of problem (5), (6) exists. This solution is defined by (7).

We pass to the inverse problem (1), (2).

Theorem 1. Assume that $\alpha \in(0,1), \varphi_{0} \in C^{2+\gamma}(\bar{\Omega}),\left.\varphi_{0}\right|_{\partial \Omega}=0, F_{0} \in C^{1+\gamma}(Q \times \mathbb{R})$,

$$
R_{v}(t)=\int_{\Omega} F_{0}(x, t, v(x, t)) \varphi_{0}(x) d x \neq 0, \quad \forall t \in[0, T], v \in C^{\gamma}(\bar{Q}) .
$$

Then the solution $(u, g) \in C^{2, \alpha}(\bar{Q}) \times C[0, T]$ of problem (1), (2) is unique.

Proof. Take two solutions $\left(u_{1}, g_{1}\right),\left(u_{2}, g_{2}\right) \in C^{2, \alpha}(\bar{Q}) \times C[0, T]$ of problem (1), (2) and substitute them into equation (1). Denoting $u=u_{1}-u_{2}, g=g_{1}-g_{2}$ we obtain the equation

$$
D_{t}^{\alpha} u-\Delta u=g_{1}(t) F_{0}\left(x, t, u_{1}\right)-g_{2}(t) F_{0}\left(x, t, u_{2}\right) .
$$

By the Hadamard lemma

$$
F_{0}\left(x, t, u_{1}\right)-F_{0}\left(x, t, u_{2}\right)=F_{01}\left(x, t, u_{1}, u_{2}\right) u(x, t)
$$

with some known, dependent on $u_{1}, u_{2}$, function $F_{01} \in C^{\gamma}(Q)$. Then the previous equation gets a form

$$
D_{t}^{\alpha} u-\Delta u=g_{2}(t) F_{01}\left(x, t, u_{1}, u_{2}\right) u+g(t) F_{0}\left(x, t, u_{1}(x, t)\right), \quad(x, t) \in Q .
$$

It follows from (2) that

$$
\begin{gathered}
\left.u\right|_{\partial \Omega \times[0, T]}=0, \quad u(x, 0)=0, \quad x \in \bar{\Omega}, \\
\int_{\Omega} u(x, t) \varphi_{0}(x) d x=0, t \in[0, T] .
\end{gathered}
$$


Since

$$
\int_{\Omega} D_{t}^{\alpha} u(x, t) \varphi_{0}(x) d x=D_{t}^{\alpha} \int_{\Omega} u(x, t) \varphi_{0}(x) d x=0,
$$

equation (9) and the over-determination condition (11) imply

$$
\begin{gathered}
\int_{\Omega} u(x, t) \Delta \varphi_{0}(x) d x= \\
=g(t) \int_{\Omega} F_{0}\left(x, t, u_{1}(x, t)\right) \varphi_{0}(x) d x+g_{2}(t) \int_{\Omega} F_{01}\left(x, t, u_{1}, u_{2}\right) u(x, t) \varphi_{0}(x) d x, t \in[0, T] .
\end{gathered}
$$

From here, using assumption (8), we find

$$
g(t)=\frac{1}{R_{u_{1}}(t)}\left[\int_{\Omega} u(z, t) \Delta \varphi_{0}(z) d z-g_{2}(t) \int_{\Omega} F_{01}\left(z, t, u_{1}, u_{2}\right) u(z, t) \varphi_{0}(z) d z\right], t \in[0, T] .
$$

As in [16] and [6] we get that for each $g \in C[0, T]$ the function $u$ is the solution of problem (9), 10) if and only if it satisfies (in $C^{\gamma}(Q)$ ) the integral equation

$$
\begin{aligned}
& u(x, t)=\int_{0}^{t} g_{2}(\tau) d \tau \int_{\Omega} G_{0}(x, t, y, \tau) F_{01}\left(y, \tau, u_{1}, u_{2}\right) u(y, \tau) d y+ \\
& +\int_{0}^{t} g(\tau) d \tau \int_{\Omega} G_{0}(x, t, y, \tau) F_{0}\left(y, \tau, u_{1}(y, \tau)\right) d y, \quad(x, t) \in \bar{\Omega} .
\end{aligned}
$$

Substituting expression 12 for $g(t)$ in 13 we obtain the integral equation

$$
\begin{aligned}
u(x, t) & =\int_{0}^{t} d \tau \int_{\Omega}\left[\frac{K(x, t, \tau) d \tau}{R_{u_{1}}(\tau)}\left(\Delta \varphi_{0}(z)-g_{2}(\tau) F_{01}\left(z, \tau, u_{1}, u_{2}\right) \varphi_{0}(z)\right)+\right. \\
& \left.+g_{2}(\tau) G_{0}(x, t, z, \tau) F_{01}\left(z, \tau, u_{1}, u_{2}\right)\right] u(z, \tau) d z, \quad(x, t) \in \bar{Q}
\end{aligned}
$$

where

$$
K(x, t, \tau)=\int_{\Omega} G_{0}(x, t, y, \tau) F_{0}\left(y, \tau, u_{1}(y, \tau)\right) d y
$$

is the known function. It follows from [15] that

$$
\left|G_{0}(x, t, y, \tau)\right| \leq \frac{C_{0}|x-y|^{2-n}}{t-\tau} e^{-c_{0}\left(\frac{|x-y|^{2}}{(t-\tau)^{\beta}}\right)^{\frac{1}{2-\beta}}}, \quad(x, t),(y, \tau) \in Q, \quad(x, t) \neq(y, \tau),
$$

and from [21], for example, that $K(x, t, \tau)$ is the continuous function in $x \in \Omega$ and

$$
|K(x, t, \tau)| \leq C(t-\tau)^{\alpha-1}, \quad x \in \Omega, 0 \leq \tau<t \leq T .
$$

Hereinafter $C_{0}, c_{0}, C, \widehat{C}, C_{i}(i \in \mathbb{N})$ are positive constants.

We get the homogeneous linear second type Volterra integral equation 14 with integrable kernel which has the unique solution $u(x, t)=0,(x, t) \in \bar{Q}$. Then from 12. we obtain $g(t)=0, t \in[0, T]$. 


\section{UNIQUENESS OF THE GENERALIZED SOLUTION}

Let

$$
\begin{gathered}
C^{m,(0)}[0, T]=\left\{\eta \in C^{m}[0, T]: \eta^{(k)}(T)=0, k=0,1, \ldots, m\right\}, \\
\mathcal{D}[0, T]=C^{\infty,(0)}[0, T], \quad \mathcal{D}(\bar{\Omega})=C^{\infty}(\bar{\Omega}), \\
\mathcal{D}(\bar{Q})=\left\{\psi \in C^{\infty}(\bar{Q}): \psi(x, \cdot) \in C^{\infty,(0)}[0, T]\right\} .
\end{gathered}
$$

We denote by $E^{\prime}$ the space of linear continuous functionals (distributions) on $E$. The symbol $(f, \varphi)$ stands for the value of the distribution $f$ on the test function $\varphi$.

In [21], the linear problem

$$
\begin{gathered}
u^{(\alpha)}(x, t)-\Delta u(x, t)=g_{0}(x, t), \quad(x, t) \in Q, \\
\left.u\right|_{\partial \Omega \times[0, T]}=0, \quad u(x, 0)=F_{1}(x), \quad x \in \bar{\Omega}
\end{gathered}
$$

was studied in the case $g_{0} \in \mathcal{D}^{\prime}(\bar{Q}), F_{1} \in \mathcal{D}^{\prime}(\bar{\Omega})$. The existence of its unique solution $u \in \mathcal{D}^{\prime}(\bar{Q})$ was established. It was shown that this solution may be given by

$$
(u, \varphi)=\left(g_{0}(\cdot, \tau),\left(\widehat{\mathcal{G}}_{0} \varphi\right)(\cdot, \tau)\right)+\left(F_{1}(\cdot),\left(\widehat{\mathcal{G}}_{1} \varphi\right)(\cdot)\right) \quad \forall \varphi \in \mathcal{D}(\bar{Q})
$$

where

$$
\begin{gathered}
\left(\widehat{\mathcal{G}}_{0} \varphi\right)(y, \tau)=\int_{\tau}^{T} d t \int_{\Omega} G_{0}(x, t, y, \tau) \varphi(x, t) d x, \\
\left(\widehat{\mathcal{G}}_{1} \varphi\right)(y)=\int_{0}^{T} d t \int_{\Omega} G_{1}(x, t, y) \varphi(x, t) d x, y \in \bar{\Omega}, \tau \in[0, T] .
\end{gathered}
$$

As in [22, p. 209], for arbitrary $u \in \mathcal{D}^{\prime}(\bar{Q}), \varphi \in \mathcal{D}(\bar{\Omega})$ we use the distribution $(u(x, \cdot), \varphi(x)) \in \mathcal{D}^{\prime}[0, T]$ acting by the formula

$$
((u(x, t), \varphi(x)), \eta(t))=(u(x, t), \varphi(x) \eta(t)) \quad \forall \eta \in \mathcal{D}[0, T]
$$

and say that the distribution $u \in \mathcal{D}^{\prime}(\bar{Q})$ is continuous at the variable $t \in[0, T]$ if $(u(x, \cdot), \varphi(x)) \in C[0, T]$ for each test function $\varphi$. We introduce the space of such distributions

$$
\mathcal{D}_{C}^{\prime}(\bar{Q})=\left\{v \in \mathcal{D}^{\prime}(\bar{Q}):(v(\cdot, t), \varphi(\cdot)) \in C[0, T] \quad \forall \varphi \in \mathcal{D}(\bar{\Omega})\right\} .
$$

In [23, for the linear problem (15) with $g_{0}(x, t)=g(t) F(x), g \in C[0, T], F, F_{1} \in$ $\mathcal{D}^{\prime}(\bar{\Omega})$ the existence and uniqueness of the solution $u \in \mathcal{D}_{C}^{\prime}(\bar{Q})$ was proved. This solution has the representation

$$
\begin{gathered}
(u(\cdot, t), \varphi(\cdot))=\int_{0}^{t} g(\tau)\left(F(y), \int_{\Omega} G_{0}(x, t, y, \tau) \varphi(x) d x\right) d \tau+ \\
+\left(F_{1}(y), \int_{\Omega} G_{1}(x, t, y) \varphi(x) d x\right) \quad \forall \varphi \in \mathcal{D}(\bar{\Omega}) .
\end{gathered}
$$

Let $\mathcal{Z}(\bar{\Omega}) \subset C^{\gamma}(\bar{\Omega})$ be the Banach space with the norm $\|\cdot\|_{\mathcal{Z}(\bar{\Omega})}$,

$$
\mathcal{Z}_{0}(\bar{\Omega})=\left\{\psi \in \mathcal{Z}(\bar{\Omega}):\left.\psi\right|_{\partial \Omega}=0\right\},
$$




$$
\begin{gathered}
\mathcal{Z}(\bar{Q})=\left\{\psi \in C^{\gamma}(\bar{Q}): \psi(\cdot, t) \in \mathcal{Z}(\bar{\Omega}) \quad \forall t \in[0, T]\right\} \\
\mathcal{X}(\bar{Q})=\left\{\psi \in C^{2, \alpha}(\bar{Q}): \widehat{L} \psi \in \mathcal{Z}(\bar{Q}),\left.\quad \psi\right|_{\partial \Omega \times[0, T]}=0\right\}, \\
\mathcal{M}=\mathcal{M}(Q)=\mathcal{Z}_{C}^{\prime}(\bar{Q})=\left\{v \in \mathcal{Z}^{\prime}(\bar{Q}):(v(\cdot, t), \varphi(\cdot)) \in C[0, T] \quad \forall \varphi \in \mathcal{Z}(\bar{\Omega})\right\},
\end{gathered}
$$

where

$$
\begin{gathered}
\widehat{L} \psi(x, t)=f_{-\alpha}(t) \hat{*} \psi(x, t)-\Delta \psi(x, t), \quad(x, t) \in Q, \\
h(t) \hat{*} \varphi(t)=(h(s), \varphi(s+t)), \quad t \in[0, T] .
\end{gathered}
$$

We consider inverse problem (3), (4) in the case $F_{1} \in \mathcal{Z}^{\prime}(\bar{\Omega}), F_{2} \in C[0, T]$. Note that the solution $u$ of the corresponding direct problem (3) may have the singularity at $t=0$.

Definition 3. A pair $(u, g) \in \mathcal{M}(Q) \times C[0, T]$ is called a generalized solution of problem (3), (4) if the identity

$$
\begin{gathered}
(u(x, t), \widehat{L} \psi(x, t))=\int_{0}^{T} g(t)\left(F_{0}(\cdot, t, u(\cdot, t)), \psi(\cdot, t)\right) d t+ \\
+\left(F_{1}(\cdot), \int_{0}^{T} f_{1-\alpha}(t) \psi(\cdot, t) d t\right) \quad \forall \psi \in \mathcal{X}(\bar{Q})
\end{gathered}
$$

and condition (4) hold.

The necessary conditions

$$
\left(F_{1}, \varphi_{0}\right)=F_{2}(0)
$$

and

$$
\left(F_{0}(x, \cdot, u(x, \cdot)), \psi(x, \cdot)\right) \in L_{1}(0, T) \forall \psi \in \mathcal{X}(\bar{Q})
$$

follow from the definition.

Assumption (A): $\varphi_{0} \in \mathcal{Z}_{0}(\bar{\Omega}), \Delta \varphi_{0} \in \mathcal{Z}(\bar{\Omega})$,

$$
\begin{gathered}
\left(F_{0}(x, \cdot, v(x, \cdot)), \varphi(x)\right) \in C[0, T] \quad \forall \varphi \in \mathcal{Z}(\bar{\Omega}), v \in \mathcal{M}(Q), \\
R_{v}(t):=\left(F_{0}(\cdot, t, v(\cdot, t)), \varphi_{0}(\cdot)\right) \neq 0 \quad \forall t \in[0, T], v \in \mathcal{M}(Q) .
\end{gathered}
$$

Let $F\left(x, t, z_{1}, z_{2}\right)=F_{0}\left(x, t, z_{1}\right)-F_{0}\left(x, t, z_{2}\right), \quad\left(x, t, z_{1}\right),\left(x, t, z_{2}\right) \in Q \times \mathbb{R}$.

It follows from (A) that

$$
\left(F\left(x, \cdot, v_{1}, v_{2}\right), \varphi(x)\right) \in C[0, T] \forall v_{1}, v_{2} \in \mathcal{M}(Q), \varphi \in \mathcal{Z}(\bar{\Omega}) .
$$

Take two solutions $\left(u_{1}, g_{1}\right),\left(u_{2}, g_{2}\right) \in \mathcal{M}(Q) \times C[0, T]$ of problem (3), (4). Denoting $u=u_{1}-u_{2}, g=g_{1}-g_{2}$, we obtain

$$
\begin{gathered}
(u(x, t), \widehat{L} \psi(x, t))=\int_{0}^{T} g(t)\left(F_{0}\left(\cdot, t, u_{1}(\cdot, t)\right), \psi(\cdot, t)\right) d t+ \\
+\int_{0}^{T} g_{2}(t)\left(F\left(\cdot, t, u_{1}, u_{2}\right), \psi(\cdot, t)\right) d t \quad \forall \psi \in \mathcal{X}(\bar{Q}),
\end{gathered}
$$


and that

$$
\left(u(\cdot, t), \varphi_{0}(\cdot)\right)=0, \quad t \in[0, T] .
$$

As in [21] we prove that $u$ satisfies identity 19 if and only if it satisfies the equation

$$
\begin{gathered}
(u, \varphi)=\int_{0}^{T} g(\tau)\left(F_{0}\left(\cdot, \tau, u_{1}(\cdot, \tau)\right),\left(\widehat{\mathcal{G}_{0}} \varphi\right)(\cdot, \tau)\right) d \tau+ \\
+\int_{0}^{T} g_{2}(\tau)\left(F\left(\cdot, \tau, u_{1}, u_{2}\right),\left(\widehat{\mathcal{G}_{0}} \varphi\right)(\cdot, \tau)\right) d \tau \quad \forall \varphi \in \mathcal{Z}(\bar{Q}) .
\end{gathered}
$$

By the results in [21, $\widehat{\mathcal{G}_{0}} \varphi \in \mathcal{X}(\bar{Q})$ for all $\varphi \in \mathcal{Z}(\bar{Q})$. Therefore, taking 17 into account, we get that the right-hand side of (21) exists.

In particular, in the case $\varphi(x, t)=\widehat{\varphi}(x) \eta(t)$ with $\widehat{\varphi} \in \mathcal{Z}(\bar{\Omega}), \quad \eta \in C^{1,(0)}[0, T]$, formula 21) gets a form

$$
\begin{gathered}
\int_{0}^{T}(u(\cdot, t), \widehat{\varphi}(\cdot)) \eta(t) d t=\int_{0}^{T} g(\tau)\left(F_{0}\left(\cdot, \tau, u_{1}(\cdot, \tau)\right), \int_{\tau}^{T} \eta(t) d t \int_{\Omega} G_{0}(x, t, \cdot, \tau) \widehat{\varphi}(x) d x\right) d \tau+ \\
+\int_{0}^{T} g(\tau)\left(F\left(\cdot, \tau, u_{1}, u_{2}\right), \int_{\tau}^{T} \eta(t) d t \int_{\Omega} G_{0}(x, t, \cdot, \tau) \widehat{\varphi}(x) d x\right) d \tau,
\end{gathered}
$$

that is

$$
\begin{aligned}
\int_{0}^{T}(u(\cdot, t), \widehat{\varphi}(\cdot)) \eta(t) d t & =\int_{0}^{T} \eta(t) d t \int_{0}^{t} g(\tau)\left(F_{0}\left(\cdot, \tau, u_{1}(\cdot, \tau)\right), \int_{\Omega} G_{0}(x, t, \cdot, \tau) \widehat{\varphi}(x) d x\right) d \tau+ \\
& +\int_{0}^{T} \eta(t) d t \int_{0}^{t} g_{2}(\tau)\left(F\left(\cdot, \tau, u_{1}, u_{2}\right), \int_{\Omega} G_{0}(x, t, \cdot, \tau) \widehat{\varphi}(x) d x\right) d \tau .
\end{aligned}
$$

By arbitrariness of $\eta$ and previous reasoning this equation may be written as follows

$$
\begin{gathered}
(u(\cdot, t), \varphi(\cdot))=\int_{0}^{t} g(\tau)\left(F_{0}\left(\cdot, \tau, u_{1}(\cdot, \tau)\right), \int_{\Omega} G_{0}(x, t, \cdot, \tau) \varphi(x) d x\right) d \tau+ \\
+\int_{0}^{t} g_{2}(\tau)\left(F\left(\cdot, \tau, u_{1}, u_{2}\right), \int_{\Omega} G_{0}(x, t, \cdot, \tau) \varphi(x) d x\right) d \tau \quad \forall t \in[0, T], \varphi \in \mathcal{Z}(\bar{\Omega}) .
\end{gathered}
$$

As in 23. we prove that the solution of this equation satisfies identity 19 and

$$
\left(D_{t}^{\alpha} u-\Delta u, \varphi\right)=\left(g_{2}(t) F\left(x, t, u_{1}, u_{2}\right)+g(t) F_{0}\left(x, t, u_{1}\right), \varphi(x)\right) \quad \forall \varphi \in \mathcal{Z}(\bar{\Omega}) .
$$

From this equation and over-determination condition 20 we get

$$
\begin{gathered}
\left(u(\cdot, t), \Delta \varphi_{0}(\cdot)\right)+g(t)\left(F_{0}\left(y, t, u_{1}(y, t)\right), \varphi_{0}(y)\right)+ \\
\quad+g_{2}(t)\left(F\left(z, t, u_{1}, u_{2}\right), \varphi_{0}(z)\right)=0, \quad t \in[0, T]
\end{gathered}
$$


and from here find

$$
g(t)=-\frac{1}{R_{u_{1}}(t)}\left[\left(u(\cdot, t), \Delta \varphi_{0}(\cdot)\right)+g_{2}(t)\left(F\left(z, t, u_{1}, u_{2}\right), \varphi_{0}(z)\right)\right], \quad t \in[0, T] .
$$

Note that according to (A) and (18), $R_{u_{1}} \in C[0, T], R_{u_{1}}(t) \neq 0, t \in[0, T]$, the function $\left(F\left(\cdot, t, u_{1}, u_{2}\right), \varphi_{0}(\cdot)\right)$ exists and belongs to $C[0, T]$.

Substituting the expression for $g$ in 22 we obtain the equation

$$
\begin{aligned}
(u(\cdot, t), \varphi(\cdot))= & -\int_{0}^{t} \frac{1}{R_{u_{1}}(\tau)}\left[\left(u(\cdot, \tau), \Delta \varphi_{0}(\cdot)\right)+g_{2}(\tau)\left(F\left(\cdot, \tau, u_{1}, u_{2}\right), \varphi_{0}(\cdot)\right)\right] \times \\
& \times\left(F_{0}\left(\cdot, \tau, u_{1}(\cdot, \tau)\right), \int_{\Omega} G_{0}(x, t, \cdot, \tau) \varphi(x) d x\right) d \tau+ \\
& +\int_{0}^{t} g_{2}(\tau)\left(F\left(\cdot, \tau, u_{1}, u_{2}\right), \int_{\Omega} G_{0}(x, t, \cdot, \tau) \varphi(x) d x\right) d \tau \forall t \in[0, T], \varphi \in \mathcal{Z}(\bar{\Omega})
\end{aligned}
$$

and that under the assumption (A) the pair $(u, g) \in \mathcal{M}(Q) \times C[0, T]$ is the solution of problem (19), 20) if and only if $u$ satisfies equation (24), $g$ is defined by (23).

From the results in [15, 21] we get that

$$
\begin{gathered}
\int_{\Omega} G_{0}(x, t, \cdot, \tau) \varphi(x) d x \in \mathcal{Z}_{0}(\bar{\Omega}) \cap C^{2+\gamma}(\bar{\Omega}) \quad \forall \varphi \in \mathcal{Z}(\bar{\Omega}), \quad 0 \leq \tau<t \leq T, \\
\left.\mid \int_{\Omega} G_{0}(x, t, y, \tau) \varphi(x) d x\right) \mid \leq \widehat{C}(t-\tau)^{\alpha-1}\|\varphi\|_{\mathcal{Z}(\bar{\Omega})}, \quad y \in \bar{\Omega}, 0 \leq \tau<t \leq T .
\end{gathered}
$$

Then, according to (A) and 18,

$$
\left(F_{0}(\cdot, \tau, v(\cdot, \tau)), \int_{\Omega} G_{0}(x, t, \cdot, \tau) \varphi(x) d x\right)
$$

and

$$
\left(F\left(\cdot, \tau, v_{1}, v_{2}\right), \int_{\Omega} G_{0}(x, t, \cdot, \tau) \varphi(x) d x\right)
$$

exist for all $\varphi \in \mathcal{Z}(\bar{\Omega}), v, v_{1}, v_{2} \in \mathcal{M}(Q), 0 \leq \tau<t \leq T$ and are integrable in $t$ and $\tau$. Therefore, under the assumption (A) the right-hand side of equation (24) exists and belongs to $C[0, T]$. 
Assumption (B): $\varphi_{0} \in \mathcal{Z}_{0}(\bar{\Omega}), \Delta \varphi_{0} \in \mathcal{Z}(\bar{\Omega})$,

$$
\begin{gathered}
\exists \int_{\Omega}\left|F_{0}(x, \cdot, v(x, \cdot))\right| d x \in C[0, T] \quad \forall v \in \mathcal{M}(Q), \\
R_{v}(t):=\int_{\Omega} F_{0}(x, t, v(x, t)) \varphi_{0}(x) d x \neq 0 \quad \forall t \in[0, T], v \in \mathcal{M}(Q), \\
\int_{0}^{t}(t-\tau)^{\alpha-1} d \tau \int_{\Omega}\left|F_{0}(y, \tau, v(y, \tau))\right| d y \text { is monotonously increasing, } \\
\exists L=\text { const }>0 \text { such that } \\
\left|\left(F_{0}\left(\cdot, t, v_{1}(\cdot, t)\right)-F_{0}\left(\cdot, t, v_{2}(\cdot, t)\right), \varphi(\cdot)\right)\right| \leq L\left|\left(v_{1}(\cdot, t)-v_{2}(\cdot, t), \varphi(\cdot)\right)\right| \\
\forall t \in(0, T], \quad v_{1}, v_{2} \in \mathcal{M}(Q), \quad \varphi \in \mathcal{Z}_{0}(\bar{\Omega}) .
\end{gathered}
$$

Theorem 2. Assume that (B) holds. Then there exists $t_{0} \in(0, T]\left(Q_{0}=\Omega \times\left(0, t_{0}\right]\right.$, respectively) such that the solution $(u, g) \in \mathcal{M}\left(Q_{0}\right) \times C\left[0, t_{0}\right]$ of problem (3), (4) is unique.

Proof. Assumption (B) implies (A) with such $F_{0}$ and $(17)$ for all $u \in \mathcal{M}(Q)$. Therefore, from the above, it is sufficient to prove that equation (24) has the unique solution $u=0$ in $\mathcal{M}\left(Q_{0}\right)$ with some $t_{0} \in(0, T]$. We denote

$$
\|v\|=\|v\|_{\mathcal{M}}=\max _{t \in[0, T]}\|v(\cdot, t)\|^{\prime}<+\infty
$$

where $\|v(\cdot, t)\|^{\prime}=\sup _{\varphi \in \mathcal{Z}(\bar{\Omega})} \frac{|(v(\cdot, t), \varphi(\cdot))|}{\|\varphi\|_{\mathcal{Z}(\bar{\Omega})}}$, and define the operator $H$ on $\mathcal{M}(Q)$ :

$$
\begin{aligned}
((H v)(\cdot, t), \varphi(\cdot)) & =-\int_{0}^{t} \frac{1}{R_{v_{1}}(\tau)}\left[\left(v(\cdot, \tau), \Delta \varphi_{0}(\cdot)\right)+g_{2}(\tau)\left(F\left(z, \tau, v_{1}, v_{2}\right), \varphi_{0}(z)\right)\right] \times \\
& \times\left(F_{0}\left(\cdot, \tau, v_{1}(\cdot, \tau)\right), \int_{\Omega} G_{0}(x, t, \cdot, \tau) \varphi(x) d x\right) d \tau+ \\
& +\int_{0}^{t} g_{2}(\tau)\left(F\left(\cdot, \tau, v_{1}, v_{2}\right), \int_{\Omega} G_{0}(x, t, \cdot, \tau) \varphi(x) d x\right) d \tau \\
\forall t & \in[0, T], \quad \varphi \in \mathcal{Z}(\bar{\Omega}), \quad v_{1}, v_{2} \in \mathcal{M}(Q), \text { and } v=v_{1}-v_{2} .
\end{aligned}
$$

By assumption (B) and properties of $G_{0}(x, t, y, \tau)$, in particular, 25 , for all $\varphi \in$ $\mathcal{Z}(\bar{\Omega})$ we get

$$
\frac{\left|\left(F_{0}\left(\cdot, \tau, v_{1}(\cdot, \tau)\right), \int_{\Omega} G_{0}(x, t, \cdot, \tau) \varphi(x) d x\right)\right|}{\|\varphi\|_{\mathcal{Z}(\bar{\Omega})}} \leq
$$




$$
\begin{gathered}
\leq \frac{\int_{\Omega}\left|F_{0}\left(y, \tau, v_{1}(y, \tau)\right)\right|\left[\int_{\Omega}\left|G_{0}(x, t, y, \tau) \varphi(x)\right| d x\right] d y}{\|\varphi\|_{\mathcal{Z}(\bar{\Omega})}} \leq \\
\leq C_{1}(t-\tau)^{\alpha-1} \int_{\Omega}\left|F_{0}\left(y, \tau, u_{1}(y, \tau)\right)\right| d y, \\
\frac{\left|\left(F\left(z, \tau, v_{1}, v_{2}\right), \int_{\Omega} G_{0}(x, t, y, \tau) \varphi(x) d x\right)\right|}{\|\varphi\|_{\mathcal{Z}(\bar{\Omega})}} \leq \\
\leq \frac{{ }_{L}\left|\left(v(y, \tau), \int_{\Omega} G_{0}(x, t, y, \tau) \varphi(x) d x\right)\right|}{\|\varphi\|_{\mathcal{Z}(\bar{\Omega})}} \leq L C_{1}(t-\tau)^{\alpha-1} \frac{|(v(\cdot, \tau), \varphi(\cdot))|}{\|\varphi\|_{\mathcal{Z}(\bar{\Omega})}} \leq \\
\leq L C_{1}(t-\tau)^{\alpha-1}|| v(\cdot, \tau) \|^{\prime}, \quad 0 \leq \tau<t \leq T .
\end{gathered}
$$

Then, denoting $a=\min _{s \in[0, T]} R_{v_{1}}(s)$, we get

$$
\begin{gathered}
\frac{|((H v)(\cdot, t), \varphi(\cdot))|}{\|\varphi\|_{\mathcal{Z}(\bar{\Omega})}} \leq \frac{C_{1}}{a\|\varphi\|_{\mathcal{Z}(\bar{\Omega})}} \int_{0}^{t}\left[\frac{\left|\left(v(\cdot, \tau), \Delta \varphi_{0}(\cdot)\right)\right|}{\left\|\Delta \varphi_{0}\right\|_{\mathcal{Z}(\bar{\Omega})}}\left\|\Delta \varphi_{0}\right\|_{\mathcal{Z}(\bar{\Omega})}+\right. \\
\left.+\frac{\left|g_{2}(\tau)\right|\left|\left(F\left(z, \tau, v_{1}, v_{2}\right), \varphi_{0}(z)\right)\right|}{\left\|\varphi_{0}\right\|_{\mathcal{Z}(\bar{\Omega})}}\left\|\varphi_{0}\right\|_{\mathcal{Z}(\bar{\Omega})}\right] \times \\
\quad \times(t-\tau)^{\alpha-1} \int_{\Omega}\left|F_{0}\left(y, \tau, v_{1}(y, \tau)\right)\right| d y d \tau+ \\
+L \int_{0}^{t}\left|g_{2}(\tau)\right| \frac{\left|\left(v(\cdot, \tau), \int_{\Omega} G_{0}(x, t, \cdot, \tau) \varphi(x) d x\right)\right|}{\|\varphi\|_{\mathcal{Z}(\bar{\Omega})}} d \tau \leq \\
\leq C_{1} \int_{0}^{t}(t-\tau)^{\alpha-1}\left[\frac{\left\|\Delta \varphi_{0}\right\|_{\mathcal{Z}(\bar{\Omega})}+\left\|\varphi_{0}\right\|_{\mathcal{Z}(\bar{\Omega})}}{a}\left|F_{0}\left(y, \tau, v_{1}(y, \tau)\right)\right| d y+\right. \\
\left.\quad+L \max _{\tau \in[0, T]}\left|g_{2}(\tau)\right|\right]\|v(\cdot, \tau)\|^{\prime} d \tau \leq \\
\leq C_{2} \int_{0}^{t}(t-\tau)^{\alpha-1}\left[1+\int_{\Omega}\left|F_{0}\left(y, \tau, v_{1}(y, \tau)\right)\right| d y\right] d \tau\|v\| .
\end{gathered}
$$

Under assumption (B) there exists $t_{0} \in(0, T]$ such that

$$
C_{3}:=C_{2} \int_{0}^{t}(t-\tau)^{\alpha-1}\left[1+\int_{\Omega}\left|F_{0}\left(y, \tau, v_{1}(y, \tau)\right)\right| d y\right] d \tau<1 \quad \forall t \in\left[0, t_{0}\right] .
$$


Therefore, we obtain

$$
\|H v\| \leq C_{3}\|v\| \quad \forall v \in \mathcal{M}\left(Q_{0}\right),
$$

and similarly,

$$
\left\|H v_{1}-H v_{2}\right\| \leq C_{3}\left\|v_{1}-v_{2}\right\| \quad \forall v_{1}, v_{2} \in \mathcal{M}\left(Q_{0}\right)
$$

with $C_{3}<1$. Therefore, $H: \mathcal{M}\left(Q_{0}\right) \rightarrow \mathcal{M}\left(Q_{0}\right)$ and is compressible. By the Banach fixed point theorem equation (24) has the unique solution $u=0$ in $\mathcal{M}\left(Q_{0}\right)$.

\section{Conclusion}

We found sufficient conditions of uniqueness of the inverse problem of the restoration a source term in a semilinear time fractional equation under integral type overdetermination condition. The cases of both regular and singular data in an initial condition was considered. The obtained result can be transferred to the case of more general equation with an elliptic second order differential expression having sufficiently regular, dependent on spatial variables coefficients.

\section{REFERENCES}

1. T. S. Aleroev, M. Kirane, and S. A. Malik, Determination of a source term for a time fractional diffusion equation with an integral type over-determination condition, Electron. J. Differ. Equ. 2013 (2013), no. 270, 1-16.

2. Y. Hatano, J. Nakagawa, Sh. Wang, and M. Yamamoto, Determination of order in fractional diffusion equation, J. Math-for-Ind. 5A (2013), 51-57.

3. M. I. Ismailov, Inverse source problem for a time-fractional diffusion equation with nonlocal boundary conditions, Appl. Math. Modelling 40 (2016), no. 7-8, 4891-4899. DOI: 10.1016/j.apm.2015.12.020

4. J. Janno and K. Kasemets, Unequeness for an inverse problem for a semilinear time-fractional diffusion equation, Inverse Problems and Imaging. 11 (2017), no. 1, 125-149. DOI: 10.3934/ipi.2017007

5. B. Jin and W. Rundell, A turorial on inverse problems for anomalous diffusion processes, Inverse Probl. 31 (2015), no. 3, 035003. DOI: 10.1088/0266-5611/31/3/035003

6. H. Lopushanska and V. Rapita, Inverse coefficient problem for semi-linear fractional telegraph equation, Electron. J. Diff. Equ. 2015 (2015), no. 153, 1-13.

7. H. Lopushanska, A problem with an integral boundary condition for a time fractional diffusion equation and an inverse problem, Fract. Differ. Calc. 6 (2016), no. 1, 133-145. DOI: $10.7153 /$ fdc-06-09

8. A. Lopushanskyj, Solvability of inverse boundary value problem for equation with fractional derivative, Visn. L'viv. Univ., Ser. Mekh.-Mat. 79 (2014), 97-110 (in Ukrainian).

9. W. Rundell, X. Xu, and L. Zuo, The determination of an unknown boundary condition in fractional diffusion equation, Appl. Anal. 92 (2012), no. 7, 1-16. DOI: $10.1080 / 00036811.2012 .686605$

10. K. Sakamoto and M. Yamamoto, Initial value/boundary-value problems for fractional diffusion-wave equations and applications to some inverse problems, J. Math. Anal. Appl. 382 (2011), no. 1, 426-447. DOI: 10.1016/j.jmaa.2011.04.058

11. Y. Zhang and $\mathrm{X}$. $\mathrm{Xu}$, Inverse source problem for a fractional diffusion equation, Inverse Probl. 27 (2011), 035010. DOI: 10.1088/0266-5611/27/3/035010

12. M. Ivanchov, Inverse problem for semilinear parabolic equation, Mat. Stud. 29 (2008), no. 2, 181-191. 
13. N. P. Protsah, Asymptotic behavior of solution of the inverse problem for weakly nonlinear ultraparabolic equation, Carpathian Math. Publ. 5 (2013), no. 2, 326-335 (in Ukrainian). DOI: $10.15330 / \mathrm{cmp} .5 .2 .326-335$

14. V. V. Anh and N. N. Leonenko, Spectral analysis of fractional kinetic equations with random datas, J. Stat. Phys. 104 (2001), no. 5-6, 1349-1387. DOI: 10.1023/A:1010474332598

15. S. D. Eidelman, S. D. Ivasyshen, and A. N. Kochubei, Analytic methods in the theory of differential and pseudo-differential equations of parabolic type, Birkhauser, Basel-BostonBerlin, 2004.

16. A. Friedman, Partial differential equations of parabolic type, Englewood Cliffs, N. J., Prentice-Hall, 1964.

17. M. I. Matijchuk, The connection between fundamental solutions of parabolic equations and fractional equations, Bukovyn. Mat. Zh. 4 (2016), no. 3-4, 101-114 (in Ukrainian).

18. A. A. Voroshylov and A. A. Kilbas, Conditions of the existence of classical solution of the Cauchy problem for diffusion-wave equation with Caputo partial derivative, Dokl. Akad. Nauk, Ross. Akad. Nauk 414 (2007), no. 4, 451-454 (in Russian); Enhlish version: Dokl. Math. 75 (2007), no. 3, 407-410. DOI: 10.1134/S1064562407030209

19. M. Caputo, Linear model of dissipation whose $Q$ is almost frequency independent-II, Geophys. J. Int. 13 (1967), no. 5, 529-539. DOI: 10.1111/j.1365-246X.1967.tb02303.x

20. M. M. Djrbashian and A. B. Nersessyan, Fractional derivatives and Cauchy problem for differentials of fractional order, Izv. AN Arm. SSR, Matematika, 3 (1968), no. 1, 3-29 (in Russian).

21. A. Lopushanskyj and H. Lopushanska, Non-homogeneous fractional boundary value problem in spaces of generalized functions, Visn. L'viv. Univ., Ser. Mekh.-Mat. 78 (2013), 92-107.

22. V. S. Vladimirov, Equations of mathematical physics, Mir, Moskow, 1984 (in Russian).

23. A. Lopushanskyj, Regularity of solutions of boundary value problems for a diffusion-wave equation with generalized functions in the right-hand sides, Carpathian Math. Publ. 5 (2013), no. 2, 279-289 (in Ukrainian). DOI: 10.15330/cmp.5.2.279-289

Стаття: надійшла до редколегї 19.04.2019 доопрацвована 18.09.2019 прийнята до друку 13.11.2019 
INVERSE SOURCE PROBLEM FOR FRACTIONAL EQUATION

ОБЕРНЕНА ЗАДАЧА ДЛЯ НАПІВЛІНІЙНОГО РІВНЯННЯ 3 ДРОБОВОЮ ПОХІДНОЮ ЗА ЧАСОМ

\author{
Галина ЛОПУШАНСЬКА, Ольга М'ЯУС \\ Лъвісъкий націоналъний університет імені Івана Франка, \\ вул. Університетсъка, 1, 79000, Лъвів, Украӥна \\ e-mail:lhp@ukr.net \\ Начіоналъний університет "Лъвівсъка політехніка", \\ вул. Бандери, 12, 79013, Лъвів, Украӥна \\ e-mail: myausolya2016@gmail.com
}

\begin{abstract}
Знаходимо достатні умови єдиності класичного та узагальненого розв'язку оберненої задачі відновлення залежного від часу неперервного множника у правій частині напівлінійного рівняння 3 дробовою похідною за часом. Використовуємо умову перевизначення інтегрального
\end{abstract} типу.

Ключові слова: похідна дробового порядку, обернена задача, умова перевизначення, вектор-функція Гріна, інтегральне рівняння. 